Relato de experiência

\title{
O ensino e aprendizagem da matemática em contexto pandêmico: com a palavra uma professora dos anos iniciais
}

\section{The teaching and learning of mathematics in a pandemic context: with the word a teacher from the early years}

\author{
La enseñanza y el aprendizaje de las matemáticas en un contexto pandémico: con la \\ palabra un maestro desde los primeros años
}

\author{
Ilvanete dos Santos de Souza ${ }^{1}$ \\ (i) [0000-0003-2467-2461] \\ Américo Junior Nunes da Silva² \\ [0000-0002-2731-8866] \\ Janete dos Anjos Vieth ${ }^{3}$ \\ [0000-0002-2731-8866]
}

\section{Resumo}

Este relato de experiência tem por objetivo apresentar algumas reflexões de uma professora que ensina Matemática nos anos iniciais sobre suas vivências da "não presença" no ensino e na aprendizagem da Matemática em tempos da pandemia da COVID-19. Trata-se de um estudo de abordagem qualitativa, orientado autobiograficamente e que põe no centro das discussões, as vivências de uma professora que ensina Matemática no 20 ano do Ensino Fundamental de uma escola pública situada no interior do estado da Bahia. Os instrumentos utilizados para a produção dos dados foram: questionário e entrevistas. Para registro dos dados produzidos, utilizamos a gravação de áudio da entrevista com a professora e de forma subsidiária, realizamos a análise das imagens do grupo de WhatsApp fornecidas por ela. Duas questões geradoras intercruzaram esta escrita: i) Os professores estavam preparados para esse novo modelo de ensino? ii) Que desafios enfrentam professores que ensinam Matemática durante a pandemia? Nessa direção, partindo das experiências relatadas, conjectura-se que: a pandemia exigiu da escola se reinventar e, consequentemente, o professor também; e de que nesse ínterim é importante perceber a formação enquanto um continuum; e que precisamos lidar com as desigualdades e a impossibilidade de oferecer, de forma equânime, um ensino remoto que atenda a todos. Importante considerar a inclusão e as tecnologias como palavras-chave não só desse momento.

Palavras-chave: Ensino de Matemática. Contexto pandêmico. Tecnologias. Desigualdades.

\section{Abstract}

1 ilvanetess@gmail.com, Mestre em Ensino de Ciências e Matemática pela UFS, professora, Secretaria Municipal de Educação Cultura, Esporte e Lazer (SMECEL), Barreiras/Bahia/Brasil.

2ajnunes@uneb.br, Doutor em Educação pela UFSCar, professor, Universidade do Estado da Bahia (Uneb Campus VII), Senhor do Bonfim/ Bahia/Brasil.

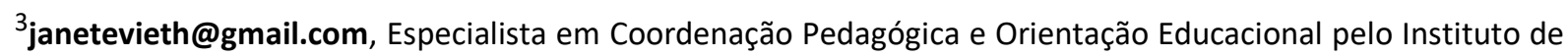
Educação Superior Unyahna, professora, Secretaria Municipal de Educação Cultura, Esporte e Lazer (SMECEL), Barreiras/Bahia/Brasil. 
This experience report aims to present some reflections of a teacher who teaches mathematics in the early years about her experiences of "not being present" in teaching and learning mathematics in times of the pandemic of COVID-19. It is an autobiographically oriented text that puts at the center of the discussions the experiences of a teacher who teaches mathematics in the 2 nd year of elementary school at a school located in the interior of the state of Bahia. Two generating questions intersect this writing: i) were the teachers prepared for this new teaching model? ii) What challenges do teachers who teach mathematics face during the Pandemic? In this sense, based on the experiences reported, it is conjectured that: the pandemic required the school to reinvent itself and, consequently, the teacher as well. In the meantime, it is important to perceive formation as a continuum; and that we need to deal with inequalities and the impossibility of offering, on an equal basis, remote education that serves everyone. It is important to consider inclusion and technologies as keywords not only at that moment.

Keywords: Mathematics teaching. Pandemic context. Technologies. Inequalities.

\section{Resumen}

Este relato de experiencia tiene como objetivo presentar algunas reflexiones de una docente que enseña Matemáticas en los primeros años sobre sus experiencias de "no estar presente" en la enseñanza y el aprendizaje de las Matemáticas en tiempos de la pandemia de COVID-19. Se trata de un texto de orientación autobiográfica que pone en el centro de las discusiones las vivencias de un docente que imparte Matemáticas en el 20 año de primaria en una escuela ubicada en el interior del estado de Bahía. Dos preguntas generadoras se cruzan en este escrito: i) ¿estaban los docentes preparados para este nuevo modelo de enseñanza? ii) ¿Qué desafíos enfrentan los maestros que enseñan Matemáticas durante la pandemia? En este sentido, a partir de las experiencias relatadas, se conjetura que: la pandemia requirió que la escuela se reinventara a sí misma y, en consecuencia, al docente también. Mientras tanto, es importante percibir la formación como un continuo; y que tenemos que afrontar las desigualdades y la imposibilidad de ofrecer, en igualdad de condiciones, una educación a distancia que sirva a todos. Es importante considerar la inclusión y las tecnologías como palabras clave no solo en ese momento.

Palabras claves: Enseñanza de las matemáticas. Contexto pandémico. Tecnologías. Desigualdades.

\section{Para início de conversa}

Ensinar e aprender Matemática no país têm se configurado, há anos, como um grande desafio; e essa realidade se agravou com o cenário de distanciamento social, enquanto medida para barrar o contágio pelo novo coronavírus. Fomos surpreendidos, em 2020, por essa pandemia e como destacou Cara (2020), esse contexto pandêmico foi a "tempestade perfeita" para alimentar uma crise que já existia; e que, como asseveraram Silva, Nery e Nogueira (2020), só escancara o quanto a Educação no Brasil é reprodutora de desigualdades.

A gravidade da situação e os riscos trazidos pelo vírus fizeram as escolas de todo o mundo repensar suas estruturas curriculares e os seus métodos de ensino. Foi inevitável a suspensão das atividades presenciais. Nesse ínterim, as atividades remotas despontaram como estratégias possíveis para mediarem a relação escola/professor/aluno/conhecimento. Perguntamos: os professores estavam preparados para esse novo modelo de ensino? Que desafios enfrentam professores que ensinam Matemática durante a pandemia? 
Este texto, objetivando ampliar o olhar acerca desses questionamentos, apresentará o relato de uma professora que ensina Matemática nos anos iniciais do Ensino Fundamental. Tratar-se-á de uma escrita narrativa, orientada autobiograficamente.

Como o relato de uma professora que ensina Matemática nos anos iniciais do Ensino Fundamental da cidade de Barreiras-BA será central nesse texto, pensamos ser esse um espaço importante para contar sobre a experiência e permitir que ela seja ouvida. Entendemos, para esse texto de uma forma particular e fundamentando-se em Clandinin e Connelly (2015), que experiências são histórias vividas pelas pessoas e que, ao contá-las, reafirmam-se, modificam-se e criam novas histórias.

Nesse ínterim, consideremos que cada ser humano se situa na vida de uma maneira específica, o que denominamos, nesse momento e respaldando-se em Natanson (1974 apud WELLER; ZARDO, 2013), de situação biográfica. O que esses sujeitos falam é importante e precisa ser considerado, principalmente, em uma perspectiva narrativa, que tanto valoriza a experiência (SILVA, 2018).

Como a experiência de vida configura-se enquanto categoria importante para esse texto; entendemos necessário fazer dois destaques: O primeiro deles refere-se ao situar o que compreendemos teoricamente em relação à experiência. Nessa direção, partindo do que nos apresenta Bondía (2002, p. 21), a entendemos como "[...] o que nos passa, o que nos aconteceu, o que nos toca. Não o que se passa, não o que acontece, ou o que toca. A cada dia se passam muitas coisas, porém, ao mesmo tempo, quase nada nos acontece".

O segundo destaque trata-se de situar o leitor que a escrita deste relato, principalmente pela natureza do que aqui é proposto, assumirá diferentes tempos verbais: na primeira pessoa do singular, quando nos referirmos, por exemplo, aos posicionamentos mais particulares da docente e a experiência vivenciada por ela, foco deste texto; na primeira e terceira pessoas do plural quando trouxermos discussões que pertencem e foram construídas a partir do contato com os autores que nos ajudaram nas discussões e a professora, em um movimento pendular de analisar a experiência vivenciada (SUZART; SILVA, 2020).

Nesse sentido, organizamos esse relato em seções; são elas: i) a introdução do texto, onde aproximamos o leitor da temática e apresentamos as perguntas que guiam à escrita; ii) o caminho da pesquisa; iii) por se tratar de um texto orientado autobiograficamente, usamos a terceira seção para nos apresentar ao leitor; iv) em seguida, após sinalizar aos participantes quem somos, relatamos as nossas experiências com o ensino e aprendizagem da Matemática durante esse período pandêmico; v) e por último, apresentamos algumas considerações.

\section{Os caminhos traçados para a construção deste relato}

Considerando o objetivado por nós neste texto, entendeu-se a necessidade de assumir uma abordagem qualitativa, com o intuito de apresentar algumas reflexões de uma professora que ensina Matemática nos anos iniciais sobre suas vivências da "não presença" no ensino e na aprendizagem da Matemática em tempos da pandemia da COVID-19.

Trata-se de um texto orientado autobiograficamente e que põe no centro das discussões as vivências de uma professora que ensina Matemática no 20 ano do Ensino Fundamental de uma escola pública situada no interior do estado da Bahia. Nesse sentido, a partir do que destacou Silva (2018), importante considerar que as narrativas, como a construção de memórias a partir das experiências do narrador, constituam-se como importante dispositivo de formação por permitir uma ruptura instauradora, reconsiderando a ideia de verdade como fixa, estável e inquestionável (GUEDES-PINTO, 2012). 
Os instrumentos utilizados para a produção dos dados foram: questionário e entrevistas. Para registro dos dados produzidos, utilizamos a gravação de áudio da entrevista com a professora e de forma subsidiaria, realizamos a análise das imagens do grupo de WhatsApp fornecidas por ela.

As categorias analíticas e a discussão dos resultados serão apresentadas na próxima seção e foram estabelecidas a partir das informações produzidas durante a entrevista, em um movimento de análise narrativa, seguindo os encaminhamentos apresentado por Silva (2018) e Silva (2021).

\section{0 ensino de matemática nos anos iniciais no período pandêmico: vou te contar uma história...}

Nesta seção, apresentamos o relato da professora sistematizado nas seguintes categorias: 3.1) Já que a palavra está comigo: conheça quem sou e a escola em que trabalho; 3.2) Início da pandemia e escolas fechadas: Fomos pegos de surpresa; 3.3) Planejamento das aulas remotas de Matemática; 3.4) Um olhar para as aulas de Matemática no contexto pandêmico. A seguir, apresentamos cada uma delas, ilustrando com imagens fornecidas pela professora.

\subsection{Já que a palavra está comigo: conheça quem sou e a escola em que trabalho}

Só para situar o leitor, penso ser necessário falar um pouco sobre mim: sou formada em Pedagogia, tenho especialização em Educação em Planejamento e Gestão Educacional pela Universidade do Estado da Bahia (UNEB); e em Coordenação Pedagógica e Orientação Educacional pelo Instituto de Educação Superior Unyahna. Atuo na docência, especificamente, com os anos iniciais, há 21 anos. Embora Huberman (2000) destaque em seus estudos que sou uma professora experiente, pelo tempo de atuação que tenho no magistério; em todos esses anos de docência nunca fui tão desafiada como agora. Lembrei-me, em alguns momentos, de meus tempos como professora iniciante, principalmente pelo "choque de realidade provocado pela pandemia. Sabe aquele tatear que caracteriza a fase de sobrevivência e descoberta do início da docência? Era assim que me sentia. A pandemia mexeu com a escola, com as famílias e, principalmente, comigo, como bem evidenciou Silva (2021) em pesquisa realizada com professores que ensinam Matemática.

Meu local de fala nesta narrativa é de professora que ensina Matemática em uma escola pública municipal, que atende apenas o ciclo de alfabetização (1ㅇ e 2 ㅇ ano), e que atua, especificamente, no 20 ano, com carga horária de 20 horas semanais. Nessa escola temos quatro turmas de $2^{\circ}$ ano, sendo duas no matutino e duas no vespertino. As turmas têm uma média de 23 crianças, com idade mínima de 7 anos e máxima de 10 anos. Entre elas estão às crianças Portadoras de Necessidades Especiais (PNE), tais como Autismo e Transtorno do Déficit de Atenção com Hiperatividade (TDAH), por exemplo.

Cabe destacar que esta escola é bastante procurada por ser referência na cidade no quesito alfabetização. As crianças matriculadas, em sua grande maioria, residem no bairro onde está localizada a escola.

\footnotetext{
${ }^{4}$ Veenman (1988);
} 


\subsection{Início da pandemia e escolas fechadas: fomos pegos de surpresa}

Com a suspensão das aulas presenciais, por meio do Decreto Municipal no 52, de 17 de março de 2020, a última aula ministrada por mim foi no dia 17 de março de 2020. Logo após o primeiro decreto, tínhamos a impressão que retomaríamos a rotina na escola em breve. No entanto, não foi isso que aconteceu. Com o passar dos dias, o contexto pandêmico se agravou e, com isso, a protelação das atividades presenciais. Como as atividades pedagógicas convencionais estavam suspensas, a gestão da escola se dispôs a oferecer aos professores os momentos de formação on-line por meio da plataforma Teams.

Nosso primeiro encontro aconteceu no dia 20 de abril de 2020. Os encontros aconteciam nas segundas, quartas e sextas-feiras; com início às 14 horas e término às 16 horas. No entanto, com o decorrer do tempo e a pedido dos participantes, foi reduzido para dois encontros semanais (segunda e quarta-feira). Porém, com início das aulas remotas, foi reduzido para um encontro por semana, na quarta-feira apenas. Essas formações foram interrompidas desde o mês de setembro devido às demandas assumidas pelos docentes.

É importante destacar que na formação continuada ${ }^{5}$, na plataforma Teams, temos uma professora universitária que colabora com a formação. Esses momentos foram denominados de "Reunião pedagógica" e o público-alvo foram os professores e monitores do 1으 e 2o ano, e teve como objetivo discutir temáticas que pudessem colaborar no processo de ensino e aprendizagem das crianças no ciclo de alfabetização.

Entendo que os desafios impostos pela contemporaneidade, como agora por conta da pandemia, mudam continuamente e, que, por isso, é importante entender que a formação de professores que ensinam Matemática é resultado de um processo dinâmico, concordando com Silva, Nery e Nogueira (2020), e que "[...] formar é mais ontológico que instruir ou educar: na formação, é o próprio ser que está em causa na sua forma" (FABRE, 1995, p. 23, tradução nossa). Por isso, nós, enquanto professores, precisamos reconhecer e assumir o nosso “(...) papel nesse percurso formativo, entendendo que existem particularidades para quem ensina essa ciência" (SILVA; NERY; NOGUEIRA, 2020, p. 103).

Como evidenciou Nóvoa $\left(2020^{6}\right)$, "[...] se existe um momento em que a formação continuada dos educadores se faz essencial, este momento é agora. Precisamos discutir e compartilhar uns com os outros e reconstruir nossas aprendizagens". Por isso, foi muito importante o movimento feito pela gestão da escola, sobretudo, no pensar parceria com a universidade, para promover esses encontros e colocar no centro da formação a nossa realidade escolar.

\subsection{Planejamento das aulas remotas de matemática}

Durante o período inicial de distanciamento social, enquanto ação para barrar o contágio pelo novo coronavírus, as atividades pedagógicas da escola estavam vinculadas apenas à formação continuada. No entanto, na última semana do mês de maio de 2020, iniciamos o planejamento para elaboração das atividades remotas. Cabe salientar que até o

\footnotetext{
5 "É nesse movimento, pendular e dialógico, existente entre formação inicial e continuada, que entendemos circunscrito o conceito de continuum" (SILVA; NERY; NOGUEIRA, 2020, p. 103).

${ }^{6}$ Informação apresentada oralmente por Antônio Nóvoa durante aula magna promovida pelo Instituto Anísio Teixeira (IAT), da Secretaria de Educação da Bahia, durante a abertura da Formação Continuada Territorial à Distância, em abril de 2020. Link: https://www.youtube.com/watch?v=7kSPWa5Nieo.
} 
momento não há nenhum decreto municipal que regularmente as atividades remotas da rede, algo que considero imprescindível.

A priori, penso ser pertinente destacar o que concebo por planejamento, até para ficar claro o meu posicionamento em relação às propostas de ensino elaboradas por mim para o período de atividades remotas. Nessa direção, concordando com o que apresentam Silva et al. (2014), planejar é um instrumento teórico e metodológico de responsabilidade principal do professor; e é com ele que se cria condições que aproximem o estudante do objeto matemático. Não se trata, portanto, de um elemento criado para atender uma demanda burocrática, longe disso; é um documento que orienta a prática do professor e professora.

Partindo dessa compreensão, organizamos alguns encaminhamentos para iniciarmos as aulas remotas. Embora o processo não tenha acontecido de forma linear, pois até o momento estamos fazendo adaptações, organizei meu planejamento da seguinte forma: nossa primeira preocupação foi, e ainda é, a forma como essas crianças irão realizar as atividades propostas remotamente e, se isso vai acontecer de forma satisfatória, considerando que os ritmos das crianças, acesso às informações e aos meios tecnológicos são diferentes. No caso da Matemática, fizemos algumas opções para reestruturar a Proposta Pedagógica da rede para esse período de pandemia. Essas opções foram pautadas também nas minhas experiências como professora que ensina Matemática para os anos iniciais desde 1999; e pensando em alguns objetos de conhecimento, fui elencando de acordo os saberes necessários à série. Repensei nas dificuldades dos alunos novatos, como também, a forma que esses conteúdos seriam vivenciados nas atividades remotas emergenciais.

Diante dessas mudanças, fui sublinhando no plano anual, os objetos de conhecimento mais pertinentes e que pudessem contemplar as habilidades do ano anterior, como também o ano atual. Com base nessa experiência e no contexto no qual atuo fiz a seleção dos objetos de conhecimento tendo por base a necessidade de adaptar o planejamento para atender as necessidades da turma (temos muitos alunos com dificuldades e que ainda não foram alfabetizados). Depois disso, houve uma segunda preocupação: "Como os objetos de conhecimento seriam expostos repassados? $E$ como as famílias compreenderiam $o$ entendimento das atividades?".

Dessa forma, fizemos um paralelo entre o currículo da rede municipal, o plano de trabalho do professor e as habilidades que possivelmente os alunos teriam condição de compreender remotamente. Contudo, em equipe, repensamos e revisamos os assuntos, embasando-nos nos documentos curriculares e reunindo um conjunto de conceitos fundamentais e os articulando; como: equivalência, ordem, proporcionalidade, interdependência, representação, enfim, e que pudéssemos contemplar uma variação e aproximação de conteúdo específico, já previstos no currículo escolar.

Após essa seleção, elaboramos os primeiros planejamentos e as primeiras atividades desenvolvidas no período de 01 a 12 de junho. Nesse período, os planejamentos eram semanais e cada turma realizava quatro atividades de Matemática por semana. Atualmente, o planejamento é quinzenal e cada turma realiza duas atividades de Matemática por semana. $\mathrm{Na}$ figura 1 abaixo, visualizamos o planejamento e as atividades estruturadas.

Na figura 1 temos o plano semanal e atividades enviadas por e-mail, para apreciação da coordenadora pedagógica, o planejamento e atividade, ambos realizados neste período.

Outro elemento que norteou a seleção dos conteúdos a serem ministrados foi a correção dos blocos de atividades devolvidos na escola (fazemos as correções dos blocos de atividades toda semana sempre na segunda-feira). Fui percebendo durante as correções das 
atividades de Matemática que algumas questões não eram respondidas, apresentavam respostas incompletas ou equivocadas. Essa situação despertou-me para retomar esses conceitos nas atividades da semana seguinte dando ênfase na exploração desses objetos do conhecimento com mais explicações e outros contextos. Isso aconteceu, por exemplo, quando trabalhei alguns conceitos de álgebra (sequência).

Figura 1- Planejamento e atividades estruturadas para a primeira semana de aula remota.
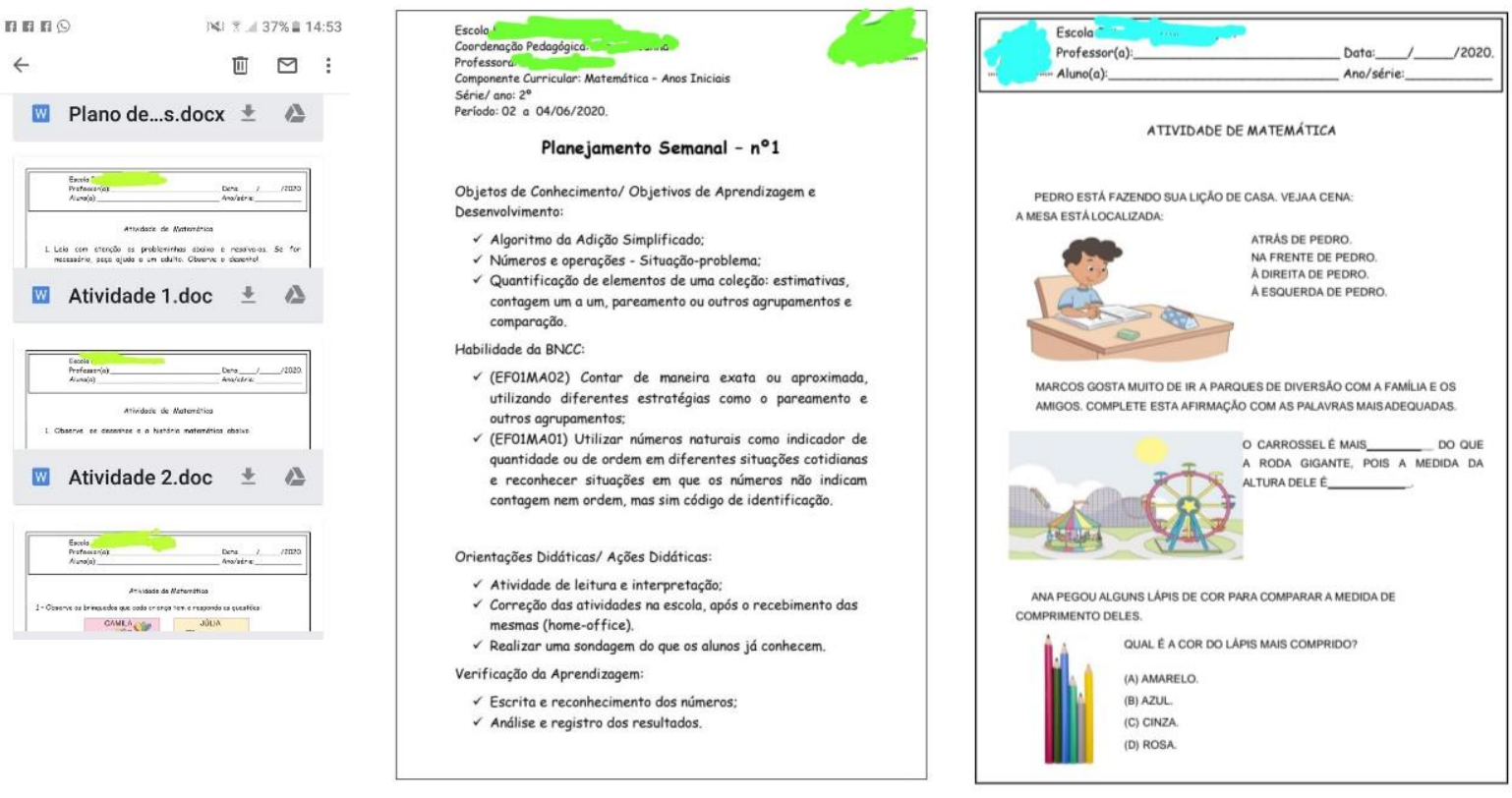

Fonte: arquivo pessoal da professora (2020).

Em suma, toda a organização do planejamento foi pensada por hipótese, porque eu não tinha certeza se de fato o que eu estava propondo seria compreendido no contexto remoto. Por exemplo, nas primeiras atividades, as crianças não respondiam algumas questões do bloco de atividades (composta por todas as atividades da semana/quinzena, impressa em folha de ofício ou imagem no e-mail corporativo). Durante a correção das atividades devolvidas na escola, a caligrafia não era da criança, mas sim de um adulto. O que nos leva a supor que não foi a criança que respondeu.

De acordo com a gestão da escola, a Secretaria Municipal de Educação, Cultura, Esporte e Lazer-SMECEL solicitou a criação de grupos de WhatsApp, por turma, com o objetivo de subsidiar a realização das atividades remotas. Inicialmente, nós professores, recebemos uma lista da escola, por e-mail, com os números dos responsáveis pelo aluno. A partir de então, criamos o grupo no dia 15 de junho, conforme figura 2.

A figura 2 retrata a criação de um grupo pela professora regente que inseriu as demais professoras, coordenadora e os responsáveis pelos alunos; e a segunda imagem da figura 2 ilustra o comunicado oficial explicando a dinâmica do grupo.

Dessa forma, conforme orientação, as aulas começaram a ser "ministradas" por WhatsApp. O que justifica essa escolha? O fato de as famílias atendidas por esta escola não terem condições financeiras para comprarem outros dispositivos móveis para as crianças. 0 objetivo desse grupo é ser um canal de interlocução entre escola e família/responsável; foi uma forma de compartilhar/oferecer suporte pedagógico para as crianças de forma remota. 
Figura 2 - Grupo criado para subsidiar as atividades remotas.
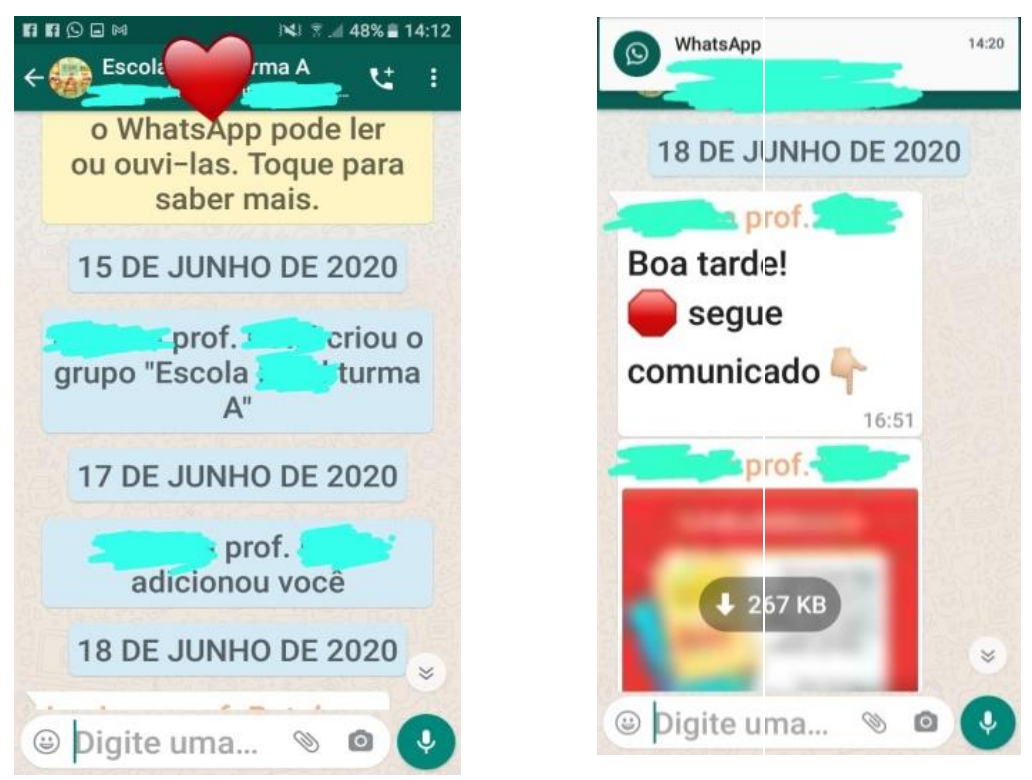

Fonte: arquivo pessoal da professora (2020).

Esse processo aconteceu de forma gradativa e foi se expandido até que todos os alunos matriculados na turma tivessem seu responsável no grupo. Vale lembrar que tiveram pais que saíram do grupo, em média três pais das quatro turmas nas quais leciono. Ao serem consultados, os pais nos informaram que não tinham interesse em continuar com o filho nessa forma de ensino e que prefeririam aguardar o retorno presencial, mesmo que fosse para o ano seguinte.

Com o objetivo de acompanhar o desenvolvimento das crianças quanto ao letramento matemático e, consequentemente, sua alfabetização, fazíamos no caderno de planejamento o mapeamento dos níveis das crianças tendo por base as respostas apresentadas nas atividades propostas. Essa prática do registro é uma rotina dos professores da escola, já anterior à pandemia. No entanto, no remoto, o registro talvez não seja tão condizente com a realidade como no presencial, uma vez que não temos como saber o contexto no qual a criança respondeu aquela atividade; se foi o pai que auxiliou ou se foi de fato à criança que compreendeu tendo por base os áudios/vídeos enviados com as explicações. Desse modo, os planos sempre terão ajustes processuais, à medida que estiver sendo executado.

Em relação à elaboração das atividades nesse componente curricular, fomos contemplando habilidades que, possivelmente, os alunos poderiam desenvolver e rememorar os conteúdos selecionados. As primeiras atividades foram diagnósticas, após a confirmação da SMECEL, mesmo assim, fomos discutindo, pelo Google Meet, possibilidades de atender a todos. Já que muitos não possuíam acesso à internet, fui elaborando atividades que pudessem motivar os alunos. Todo esse planejamento e elaboração das atividades eram feitos semanalmente, e eu estava consciente que essas atividades poderiam ter um resultado positivo ou não, porque muitas crianças, possivelmente não teriam um auxílio em domicílio, uma vez que os pais trabalham e alguns têm baixa escolaridade. Isso me preocupava, mas mesmo assim, inicialmente, fui elaborando atividades que seguiam uma sequência das atividades anteriores. 
Iniciamos com o planejamento assim que as aulas remotas foram liberadas e eram enviados para o e-mail da coordenação, conjuntamente com as atividades. Com o passar do tempo, a SMECEL exigiu que nós, professores, fizéssemos o preenchimento do formulário, composto por: identificação, encaminhamento metodológico, recursos, relatórios/resultados, modelos de atividades, vídeos e links, condizente com os planos de aula. Esse formulário é enviado mensalmente para SMECEL e uma via fica arquivada na escola.

\subsection{Um olhar para as aulas de Matemática no contexto pandêmico}

Após orientações para o ensino remoto no município, realizamos a organização do planejamento, bloco de atividades, videoaulas dos objetos de conhecimento, explicação das atividades e grupos de WhatsApp. Esses elementos sustentam o que denominamos neste relato de "aulas" remotas assíncronas.

A partir das vivências das aulas remotas aconteciam os ajustes, que eram feitos com a intenção de promover a aprendizagem dos estudantes. Um exemplo que ilustra essa evolução é a forma como organizamos as postagens nos grupos de WhatsApp e a gravação dos vídeos com a explicação das atividades. Na figura 3, a seguir, podemos visualizar a agenda diária postada pela coordenadora conforme o horário da escola (essa configuração teve início em agosto). Após a agenda, a professora responsável pela disciplina do dia faz a postagem de uma figurinha motivacional, seguindo do vídeo explicativo da atividade e logo após a imagem da atividade.

Figura 3- Postagens no grupo de WhatsApp pela coordenadora e professora de Matemática.

AGENDA - 12/11/2020 - QUINTA-FEIRA - 20 ano

\section{- Língua Portuguesa:}

Atividade na folha xerografada, envolvendo ortografia e gramática. Seguir orientações postadas no grupo, pela professora.

- Matemática:

Cálculos de adição e subtração, sequência numérica e ábaco. Seguir as orientações postadas no grupo, pela professora.

- Educação Física: Desafio do ritmo.

Assistir ao vídeo e tentar reproduzir os movimentos e sons.

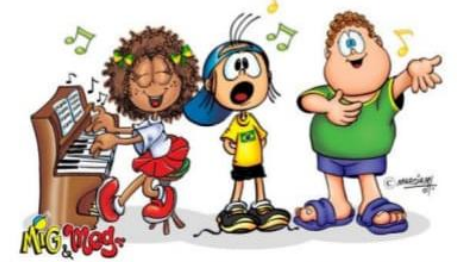

Caso tennam duvidas, coloque no grupo que responderemos!

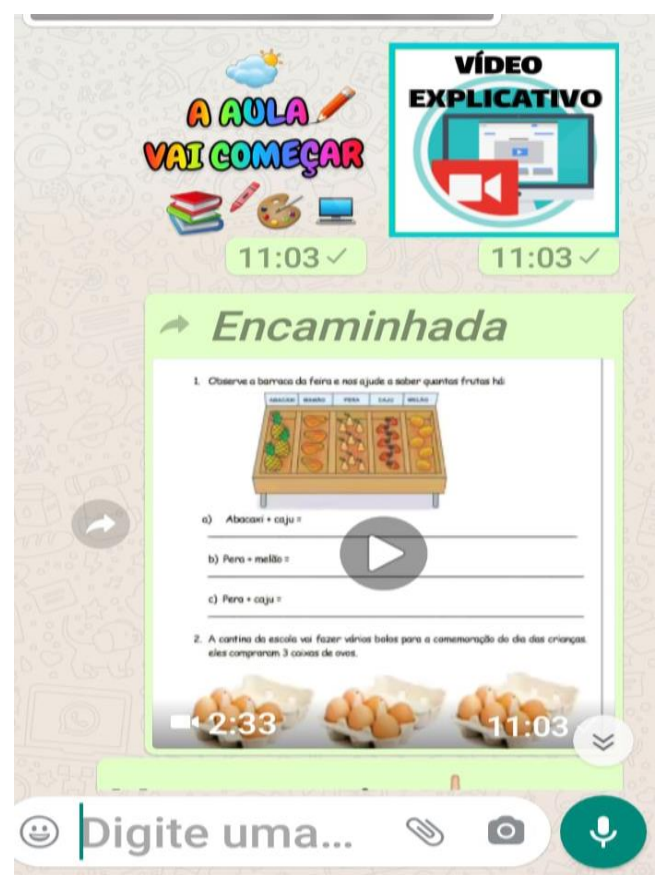

Fonte: arquivo pessoal da professora (2020).

Desde o início das aulas remotas, a escola disponibilizava as atividades de forma impressa para ser retirada na escola pelo responsável. Antes, o bloco de atividades era para ser desenvolvido pela criança durante uma semana, e após respondê-lo devolver na escola 
para apreciação/avaliação. No momento, esses blocos são quinzenais. Outros pais preferem acompanhar as atividades por meio da imagem da atividade postada no grupo de acordo com a agenda, temos um exemplo na figura 3 acima.

Após receber os blocos de atividades, as demais ações desencadeiam-se por meio do grupo de WhatsApp ou ligações por celular realizada pelo responsável sem definição de dia ou horário para atendimento. A premissa é: "quando o responsável tem tempo" e pode disponibilizar o celular e/ou auxiliar a criança na realização das atividades. Dessa forma, não conseguimos estabelecer rotina para esse contexto. Para ilustrar o modo como fazemos a postagem no grupo, observemos a figura 3, em que fiz a postagem de uma figurinha motivacional, seguindo do vídeo explicativo da atividade e logo após a imagem da atividade.

Outro ponto que merece destaque são alguns vídeos curtos do YouTube que usamos esporadicamente para complementar as explicações das atividades remotas. Mas, nesse sentido, preferia eu mesma gravar os vídeos; como conheço as crianças, faço uso de uma linguagem mais acessível e que elas compreendem melhor. Alguns responsáveis e crianças sinalizaram que quando eu explico parece que elas estão na sala.

Por meio do grupo também tiramos algumas dúvidas, recebemos atividades respondidas, realizamos as correções, devolutivas e justificativas da não entrega das atividades na data prevista. Alguns responsáveis preferem usar o privado para realizar essas ações. Na figura 4, a seguir, podemos visualizar algumas dessas conversas de WhatsApp. Nessa figura, a mãe solicitou explicação de uma questão da atividade de Matemática, pois não compreendeu o que era para fazer. A professora respondeu fazendo uso de uma linguagem Matemática para uma linguagem mais ilustrativa "vem depois". Na imagem seguinte, a professora realizou as correções e faz uma observação. Logo após, é justificada a não entrega da atividade na data prevista. A sequência de imagem é concluída com a resposta da professora à justificativa da mãe.

Observa-se ainda nos grupos, que as atividades assíncronas são postadas no grupo de WhatsApp, de modo recorrente, no período da noite (quando os pais chegam do trabalho) ou no final de semana, sábado e domingo. Outra observação é que algumas crianças não participam do grupo e entregam a atividade na escola.

Sobre a aprendizagem, durante esse período, é uma incógnita, porque nem todos os alunos participam do grupo de WhatsApp e nem tampouco devolvem as atividades; os que devolvem, em alguns momentos, fica perceptível que algumas atividades não têm a letra do aluno ou estão incompletas. Dessa forma, não temos como afirmar que essas crianças submetidas às atividades no contexto remoto conseguem aprender de forma satisfatória e sejam consideradas ao final do ano letivo "alfabetizadas". 
Figura 4- Conversas de WhatsApp.
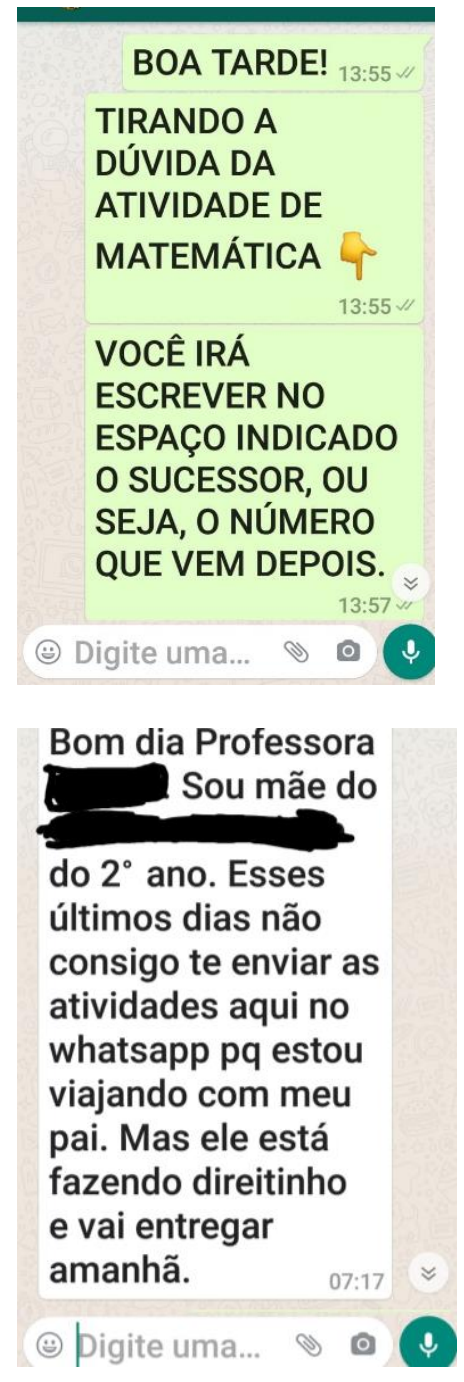
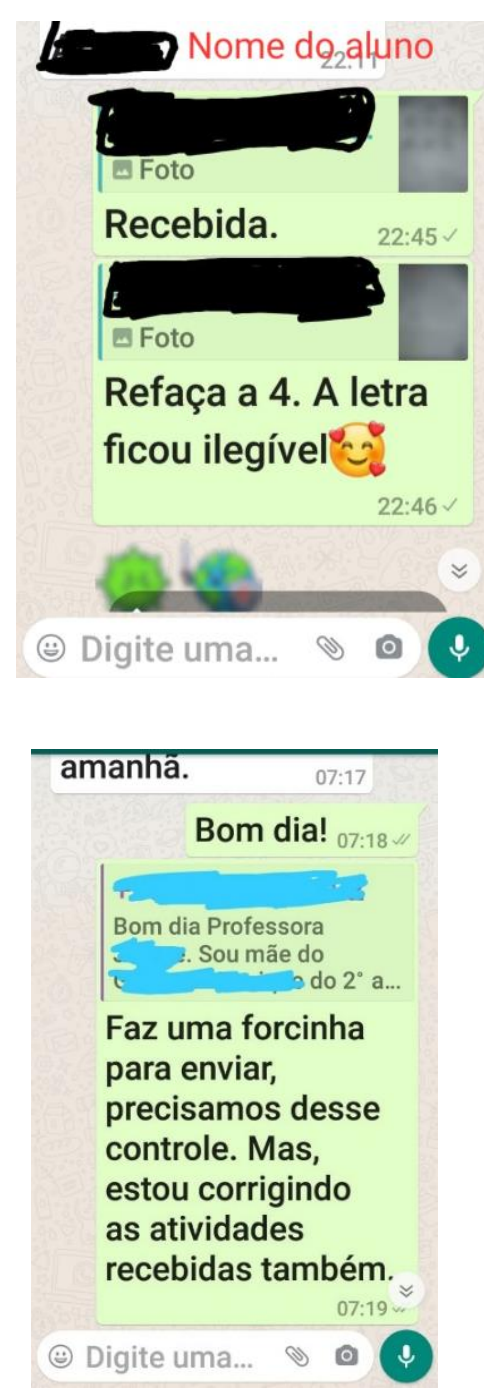

Fonte: arquivo pessoal da professora (2020).

\section{Para não concluir...}

Engraçado como tudo que é novo nos deixa um pouco apreensivos. Ao longo desses últimos meses de distanciamento social, fui me adaptando às novas normas a partir dos decretos municipais e estaduais que saiam semanalmente; sempre na expectativa que retornássemos as aulas presencialmente, mas isso não foi possível. Então, cada dia eu buscava compreender melhor a situação [com a qual nunca tinha vivenciado em meus 21 anos de docência], mas ao mesmo tempo ficava ansiosa, porém sem deixar a ansiedade atrapalhar o meu trabalho. Busquei "forças" nos relatos de outras colegas e fomos juntas nos unindo virtualmente. Isso, de certa forma, colaborou muito para aprendermos dia a dia a lidar com a situação; fui fazendo mais formações on-line e lendo sobre o Ensino Remoto.

Portanto, fui me adequando: o que não dava certo, eu refletia e refazia de outra maneira com mais comodidade e clareza como, por exemplo, a gravação dos vídeos, no Play Store, com as explicações do objeto de conhecimento e atividades. A forma como faço agora, 
depois de inúmeras tentativas, diminuíram as perguntas dos pais e questões sem repostas o que suponho que estejam compreendendo melhor.

Não sabemos ao certo como vai ser a educação, tudo está muito incerto, muita coisa terá que ser repensada e reavaliada. O currículo passará por diversas alterações, tenho certeza. Além disso, temos que saber lidar com o emocional, tanto nosso como dos alunos. Foram inúmeras notícias correlacionadas com a pandemia que nunca tínhamos vivenciado: perdas em massa, noticiários, isolamento social, enfim... Temos pela frente um ano de incertezas e angústias, mas nós professores somos persistentes; mesmo no caos, como esse agora, nos adaptamos ao "novo normal".

Contudo, as medidas protetivas deverão continuar, mas, infelizmente, os estabelecimentos de ensino da nossa cidade não estão preparados para atender a demanda e muito menos, preparar os espaços físicos em condições favoráveis à higienização, conforme estabelece a Organização Mundial de Saúde.

Já se passou tanto tempo, algo inesperado para nós educadores e estamos ainda apreensivos de como ensinar remotamente, já que não conseguimos atender a todos os alunos, além de alguns que acabaram desistindo por problemas pessoais como: deslocamento, internet, entre outros.

A maior dificuldade quanto ao ensinar remotamente a Matemática, enfrentada por mim, foi usar os aplicativos, realizar a correção e tirar dúvidas dos pais e responsáveis pelo telefone, com todos sem exceção de horários e dia da semana. Eu só trabalho 20 horas, mas tenho trabalhado todos os dias, à noite e final de semana, para atender a todos de forma satisfatória.

Nunca deixei de estar preocupada, mas estamos em uma luta incessante para atender a todos, mesmo não conseguindo. Todas as aulas estão incidindo através do nosso celular, computador pessoal e internet; não recebemos auxílio nenhum do governo, estamos também pagando com o nosso salário que não houve acréscimo nenhum. Ensinar e aprender Matemática num país emergente, requer de nós educadores, eficiência, prazer e motivação, sendo um grande desafio. Essa realidade, que apresentamos anteriormente, se agrava com o cenário de distanciamento social e tecnológico, pois muitos alunos não têm acesso.

Portanto, para não concluir este relato, retomaremos alguns questionamentos que fizemos no início do texto e para os quais tentamos ampliar o olhar ao longo da apresentação da experiência: Os professores estavam preparados para esse novo modelo de ensino? Como foi dito, ao longo da narrativa apresentada, a pandemia exigiu da escola se reinventar e, consequentemente, o professor também. Não estávamos preparados para esse novo cenário e todo esse movimento nos fez perceber, ainda mais, a formação enquanto um continuum.

Que desafios enfrentam professores que ensinam Matemática durante a pandemia? Não só os professores que ensinam Matemática, mas todos estão precisando lidar com as desigualdades e a impossibilidade de oferecer, de forma equânime, um ensino remo to que atenda a todos. Importante considerar a inclusão e as tecnologias como palavras-chave não só desse momento.

\section{Referências}

BONDÍA, Jorge Larrosa. Notas sobre a experiência e o saber de experiência. In: Revista Brasileira de Educação, Rio de Janeiro, Janeiro/Abril, 2002, p. 21-28. 
CARA, Daniel. Congresso Virtual UFBA 2020. IN. Mesa de abertura: "Educação: desafios do nosso tempo", Salvador, maio de 2020. Link: https://www.youtube.com/watch?v=6w0vELx0EvE.

CLANDININ, Jean; CONNELLY, Michael. Pesquisa Narrativa: experiência e história em pesquisa qualitativa. Uberlândia: EDUFU, 2015.

FABRE, Michel. Penser la formation. Paris: PUF, 1995.

GUEDES-PINTO, Ana Lúcia. Memorial de Formação: registro de um percurso. Faculdade de Educação da Unicamp, Campinas, 2012.

HUBERMAN, Michael. O ciclo de vida profissional dos professores. In: Nóvoa, Antônio (Org.). Vida de professores. 2. ed. Porto, Portugal: Porto Ed, 2000, p. 31-61.

SILVA, Américo Junior Nunes da. Querido diário... o que revelam as narrativas sobre ludicidade, formação e futura prática do professor que ensina(rá) matemática nos anos iniciais. 2018. Tese (Doutorado em Educação) - Universidade Federal de São Carlos, campus São Carlos, São Carlos. 2018.

SILVA, Américo Junior Nunes da; NERY, Érica Santana Silveira; NOGUEIRA, Cleia Alves. Formação, tecnologia e inclusão: o professor que ensina Matemática no "novo normal". In: Plurais Revista Multidisciplinar, v. 5, n. 2, 2020, p. 97-118.

SILVA, Américo Junior Nunes da; SOUSA, Ilvanete dos Santos; BARROS, Simone Santos; ALMEIDA, Jefferson Dias Silva. O Professor de Matemática e o Ato de Planejar: Há Unicidade entre a Dimensão Política e a Dimensão Pedagógica? In: SILVA, Américo Júnior Nunes da; SOUSA, Ilvanete dos Santos (Org). A Formação do Professor de Matemática em Questão: reflexões para um ensino com significado, Jundiaí: Paco Editorial. 2014.

SILVA, Américo Junior Nunes da. Memoriais de formação e os percursos de construção do puzzle de pesquisa. Research, Society and Development, [S. I.], v. 10, n. 1, p. e54410112162, 2021.

SILVA, Américo Junior Nunes da. Professores de matemática em início de carreira e os desafios (im)postos pelo contexto pandêmico: um estudo de caso com professores do semiárido baiano. doi.org/10.29327/217514.7.1-5. Revista Ibero-Americana de Humanidades, Ciências e Educação, [S. I.], v. 7, n. 1, p. 17, 2021.

SUZART, Leonardo Araújo; SILVA, Américo Junior Nunes da. O estágio supervisionado e o constituirse professor de matemática: "Ser ou não ser professor?". Educação Básica Revista, [S. I.], v. 6, n. 1, p. p.131-141, 2020.

VEENMAN, Simon. El proceso de llegar a ser profesor: un análisis de la formación inicial. In: VILLA, Alberto. (Coord.). Perspectivas y problemas de la función docente. Madrid: Nárcea, 1988, p. 39-68.

WELLER, Wivian; ZARDO, Sinara Pollom. Entrevista narrativa com especialista: aportes metodológicos e exemplificação. In: Revista da FAEEBA - Educação e Contemporaneidade, Salvador, julho/dezembro 2013, p. 131-143. 